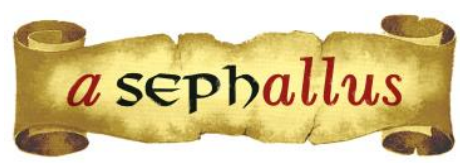

Revista aSEPHallus de Orientação Lacaniana

Núcleo Sephora de Pesquisa sobre o Moderno e o Contemporâneo

ISSN $1809-709$ X

\begin{abstract}
A exigência psíquica dos rituais de despedida diante da morte em uma UTI da COVID-19 (SarsCoV-2)
\end{abstract}

\author{
Juliana Bassoli Santos Soares \\ Orcid: https://orcid.org/0000-0002-7031-4780 \\ Psicanalista
}

Mestre em Psicologia pelo Centro de Ensino Superior de Juiz de Fora/CES (Juiz de Fora, Minas Gerais, Brasil)

Psicóloga hospitalar intensivista e gerente assistencial da Casa de Caridade de Muriaé Hospital São

Paulo/CCMHSP (Muriaé, Minas Gerais)

Email: jubassoli@hotmail.com

Patrícia Matos Rodrigues

Orcid: https://orcid.org/0000-0002-2474-4165

Psicanalista

Doutora em Teoria Psicanalítica pela Universidade Federal do Rio de Janeiro/UFRJ (Rio de Janeiro, Brasil)

Membro Adjunto Instituto Sephora de Ensino e Pesquisa de Orientação Lacaniana/ISEPOL (Rio de Janeiro,

Brasil)

E-mail: pmrpsi@gmail.com

\begin{abstract}
Resumo: 0 presente artigo visa analisar como a pandemia da COVID-19 (Sars-CoV-2) vem impactando o trabalho do psicólogo intensivista na Casa de Caridade de Muriaé Hospital São Paulo (CCMHSP). A assistência psicológica da CCMHSP orienta-se pelo viés da psicanálise aplicada ao contexto hospitalar. Em função do alto risco de contágio da COVID-19 (Sars-CoV-2), as famílias estão sendo impedidas de acompanhar de perto o processo da doença e da morte, dificultando a vivência do luto. Quais as consequências disso para os sujeitos? Pensamos que as consequências psíquicas estão para todos os envolvidos: profissionais de saúde, pacientes e familiares. Analisamos fragmentos das experiências hospitalares durante a epidemia da COVID-19 (Sars-CoV-2) para refletir se os ritos de despedidas são uma exigência psíquica diante do processo da morte e do luto de um ente querido. A construção teórica desse artigo acompanhou de perto a prática no hospital e suas manifestações diárias. O ofício da psicóloga intensivista nos faz afirmar que os rituais de despedida são uma exigência do nosso psiquismo.
\end{abstract}

Palavras-chave: COVID-19 (Sars-CoV-2); psicanálise; psicologia hospitalar; luto.

The psychic demand of farewell rituals in the face of death in the COVID-19 (Sars-CoV-2) ICU: This article aims to analyze how the COVID-19 (Sars-CoV-2) pandemic has been impacting the work of the intensive psychologist at the Muriaé Hospital São Paulo Charity House (CCMHSP). The psychological assistance of the CCMHSP is guided by the bias of psychoanalysis applied to the hospital context. Due to the high risk of contagion of COVID-19 (Sars-CoV-2), families are being prevented from closely monitoring the process of illness and death, making it difficult to experience grief. What are the consequences of this for the subjects? We think that the psychological consequences are for everyone involved: health professionals, patients and family members. We analyzed fragments of hospital experiences during the COVID-19 (SarsCoV-2) epidemic to reflect on whether farewell rites are a psychological requirement in the face of the death and grief of a loved one. The theoretical construction of this article closely followed the practice in the hospital and its daily manifestations. The job of the intensive psychologist makes us claim that farewell rituals are a requirement of our psyche.

Keywords: COVID-19 (Sars-CoV-2); psychoanalysis; hospital psychology; mourning. 
L'exigence psychique des rituels d'adieu face à la mort dans une l'USI COVID-19 (Sars-CoV-2): Cet article vise à analyser comment la pandémie de COVID-19 (Sars-CoV-2) a eu un impact sur le travail du psychologue intensif de l'hôpital Muriaé de São Paulo Charity House (CCMHSP). L'assistance psychologique du CCMHSP est guidée par le biais de la psychanalyse appliquée au contexte hospitalier. En raison du risque élevé de contagion du COVID-19 (Sars-CoV-2), les familles sont empêchées de surveiller de près le processus de maladie et de décès, ce qui rend difficile le deuil. Quelles en sont les conséquences pour les sujets? Nous pensons que les conséquences psychologiques sont pour toutes les personnes impliquées: les professionnels de santé, les patients et les membres de la famille. Nous avons analysé des fragments d'expériences hospitalières pendant l'épidémie de COVID-19 (Sars-CoV-2) pour déterminer si les rites d'adieu sont une exigence psychologique face à la mort et au chagrin d'un être cher. La construction théorique de cet article a suivi de près la pratique à l'hôpital et ses manifestations quotidiennes. Le travail du psychologue intensif nous fait affirmer que les rituels d'adieu sont une exigence de notre psyché.

Mots-clés: COVID-19 (Sars-CoV-2); psychanalyse; psychologie hospitalière; deuil. 


\title{
A exigência psíquica dos rituais de despedida diante da morte em uma UTI da COVID- 19 (Sars-CoV-2)
}

\author{
Juliana Bassoli Santos Soares \& Patrícia Matos Rodrigues
}

O presente artigo visa analisar como a pandemia da COVID-19 (Sars-CoV-2) vem impactando o trabalho do psicólogo intensivista na Casa de Caridade de Muriaé Hospital São Paulo (CCMHSP). A CCMHSP é referência em saúde desde 1927 para uma microrregião composta por 13 municípios, atingindo uma população de 1 milhão de pessoas na zona da mata mineira. A CCMHSP é um hospital geral filantrópico e sem fins lucrativos e tornou-se referência para o tratamento da COVID-19 (Sars-CoV-2).

Muriaé é um município brasileiro do estado de Minas Gerais localizado na zona da mata mineira. Sua população estimada é de 108.763 habitantes. O município é o 290 mais populoso do estado e o $3^{\circ}$ da zona da mata. A cidade é a $22^{a}$ maior aglomeração urbana em número de habitantes no estado e também a $3^{a}$ da zona da mata, depois de Juiz de Fora e Ubá. Além da CCMHSP, a cidade também conta com a Fundação Cristiano Varella - Hospital do Câncer de Muriaé -, a Casa de Saúde Santa Lúcia de Muriaé, o Prontocor - Hospital do Coração - e com o serviço de atendimento móvel de urgência - SAMU.

Diante da pandemia da COVID-19 (Sars-CoV-2), a prefeitura de Muriaé aderiu ao plano "Minas Consciente - Retomando a economia do jeito certo". Trata-se de um planejamento do estado de Minas Gerais para o enfrentamento da doença baseado em critérios e dados epidemiológicos. No entanto, o plano autoriza que cada prefeito decida sobre a implementação ou não das medidas, respeitando a autonomia dos municípios. Frente a isso, o Comitê Extraordinário Covid-19 de Muriaé deliberou pelo funcionamento monitorado do comércio para além dos serviços essenciais.

Em situação de enfrentamento da pandemia da COVID-19 (Sars-CoV-2), os fluxos de atendimentos de todas as clínicas da CCMHSP sofreram adaptações. Em tempo recorde e com um esforço substancial, as equipes alteraram suas formas de triagem, seus espaços clínicos, reforçaram a utilização de equipamentos de proteção individual (EPI) e dos instrumentos de trabalho. $O$ principal intuito esteve centrado na segurança da equipe e na assistência segura e eficaz também ao paciente. A CCMHSP possui uma equipe multidisciplinar de assistência ao paciente composta por médicos, enfermeiros, psicólogos, assistentes sociais, nutricionistas, fisioterapeutas, farmacêuticos e fonoaudiólogo. 
A instituição destinou uma área de atendimento privativo aos pacientes que apresentassem sinais ou sintomas respiratórios. Os demais pacientes continuaram sendo atendidos no fluxo normal do hospital. A área restrita para os pacientes da COVID-19 (Sars-CoV-2) foi devidamente adequada às normas e exigências dos órgãos regulamentadores. Inclusive, a equipe é exclusiva para tais atendimentos e foi treinada para buscar o máximo de segurança e qualidade. Em caso de internação, o paciente é encaminhado ao setor de destino por elevador privativo. Um andar exclusivo foi disponibilizado para tratamento dos pacientes suspeitos ou confirmados da COVID-19 (Sars-CoV-2).

A CCMHSP comporta quatro UTIs: geral, cardiológica, neonatal e COVID-19 (Sars-CoV-2). A UTI da COVID-19 (Sars-CoV-2) apresenta doze leitos. No setor, médicos de rotina intensivistas e plantonistas especializados se revezam nos cuidados com os pacientes críticos. A orientação do protocolo médico da CCMHSP acompanha as recomendações do Ministério da Saúde, da Secretaria Estadual de Saúde e da Sociedade Brasileira de Infectologia. Além dos médicos, enfermeiros, técnicos de enfermagem, fisioterapeutas, nutricionistas e fonoaudiólogo também oferecem assistência ao paciente do setor.

Um reforço à alta qualidade técnica de cada profissional de saúde da UTI da COVID-19 (Sars-CoV-2) foi a continuidade da parceria já existente com o Hospital Israelita Albert Einstein, de São Paulo. A colaboração acontece através do projeto estudo denominado "Telescope Trial". Juntamente com o incansável trabalho dos médicos e da equipe de saúde da UTI da COVID-19 (Sars-CoV-2) da CCMHSP, um médico intensivista do Hospital Einstein realiza teleconsultoria médica diária.

No tocante ao suporte psicológico aos familiares dos pacientes da COVID-19 (Sars-CoV-2) foram montados fluxos inéditos, em conformidade com as exigências do momento de pandemia. Uma das principais mudanças ocorreu e vem sendo vivenciada na unidade de tratamento intensivo - UTI. As famílias dos pacientes suspeitos ou confirmados da UTI da COVID-19 (Sars-CoV-2) não são autorizadas, como de costume, a visitarem seus familiares internados. A UTI exclusiva para atendimento de tais pacientes é considerada setor de alto risco de contaminação. Nesse ambiente não há fluxo de pessoas, além dos profissionais que são previamente autorizados, treinados e paramentados. O contato com a equipe de profissionais é realizado somente por telefone.

A assistência psicológica da CCMHSP orienta-se pelo viés da psicanálise aplicada ao contexto hospitalar. 0 trabalho de psicanálise aplicada organizado na CCMHSP pressupõe, desde 0 seu início, que a prática analítica no contexto hospitalar é possível e importante. A especificidade dessa prática sempre se guiou na manutenção do discurso analítico que visa a palavra e a subjetividade como garantias do trabalho psíquico.

Nesse momento pandêmico, a equipe multidisciplinar optou pelo seguinte protocolo de trabalho: o boletim médico é liberado pelo setor uma vez ao dia e a leitura deste é realizada, preferencialmente, pelo profissional da psicologia. Tal medida visa um esforço conjunto de 
informar e atender a família que, nessa circunstância atípica, não pode ter nenhum contato físico com o familiar doente. Mediante tal situação excepcional, os desafios foram surgindo, especialmente com relação às demandas emocionais dos familiares. É importante ressaltar que passa a ser norma que o anúncio de gravidade do quadro ou mesmo o óbito seja feito por ligação telefônica.

No texto O mal-estar na civilização (1929/1974b), Freud assinalou os recursos úteis que o homem utiliza de forma a recriar e ampliar os limites de funcionamento de seus próprios órgãos. Ele exemplificava, entre outros, que o uso do telefone amplia as distâncias que podem ser consideradas inatingíveis. Para ele, esses recursos inventados pelos homens, através da ciência e da tecnologia, são suas aquisições culturais e devem ser utilizadas como verdadeiras próteses.

Visionário, ele ainda considerava que no futuro haveria inimagináveis avanços no campo da civilização. Todos esses recursos visavam, a seu ver, minimizar o desamparo humano e contornar suas insuficiências (Freud, 1929/1974b, p. 109). A pandemia da COVID-19 (Sars-CoV2), mais do que nunca, ressalta a força da tecnologia e nos convoca a usá-la como aliada para contornar nossas limitações e impossibilidades.

No hospital não foi diferente. A nova modalidade de suporte psicológico aos familiares via telefone aparece como uma substituição possível. A prática rotineira dos psicólogos intensivistas sofreu uma alteração significativa na interação entre paciente, equipe multidisciplinar e família, especialmente por conta da interrupção da presença física no ambiente de tratamento. A entrada de um paciente na UTI ganhou a difícil realidade da suspensão das curtas visitas dos familiares.

Os psicólogos intensivistas foram orientados pelo comitê da COVID-19 (Sars-CoV-2) do hospital a não adentrarem rotineiramente na UTI. Tal medida objetiva restringir ao máximo o fluxo de profissionais no setor e, assim, diminuir a possibilidade de contágio comunitário. Sendo assim, familiares e profissionais tiveram um impacto no acompanhamento da hospitalização do paciente. Caso o óbito se consolide, há ainda o impedimento da despedida, na medida em que é público e conhecido que os velórios e os enterros, em casos de pessoas infectadas pela COVID-19 (SarsCoV-2), são devidamente limitados.

O esforço do trabalho multidisciplinar diante da COVID-19 (Sars-CoV-2) é uma tentativa de assegurar os direitos de todos, muito bem executado pelo serviço social da instituição. $O$ assistente social monitora o direito da família de ter contato com o profissional médico que presta assistência ao paciente. Por sua vez, o serviço de enfermagem também é muito atuante para a atualização constante da evolução clínica do paciente. Coube à equipe de psicologia buscar novas formas de acolher a urgência subjetiva das famílias diante de uma doença nova, de tratamento incerto e potencialmente letal, em alguns casos.

A interlocução entre as clínicas foi fundamental, pois havia a dificuldade de entendimento dos termos técnicos médicos, somado ao desconhecimento inicial da doença. O profissional de psicologia precisa, então, assegurar-se de que eles sejam interpretados corretamente para que a 
família tenha um acompanhamento da real situação clínica do paciente. Frente a isso, o auxílio da enfermagem é fundamental, na medida em que eles detalham a coleta dos dados clínicos e fazem um intercâmbio entre o paciente, seu quadro clínico e a equipe multidisciplinar.

A adesão da equipe multidisciplinar frente às propostas de intervenção da psicologia possibilita que o trabalho possa acontecer com êxito. O foco da psicologia é propiciar que a família acompanhe a melhora ou a piora do paciente e seja amparada frente a realidade de cada caso. A aposta inabitual no contato por telefone com a família tem focado em minimizar o impacto negativo dessa nova relação com o hospital no acompanhamento do quadro clínico do paciente. No entanto, mesmo com o suporte psicológico telefônico, diante da angústia, algumas famílias insistem em ir ao hospital em busca de outra forma de comunicação. Em cada situação, a equipe multidisciplinar avalia o que pode ser feito e se há a possibilidade de um contato com o médico responsável pelo caso.

A escuta técnica do psicólogo intensivista objetiva contribuir com uma nova maneira de vivência da experiência da doença, da morte e do luto. A leitura do boletim médico diário vem junto com o suporte psicológico da família. Em um dos casos vivenciados pela coordenadora da equipe de psicologia, o paciente, um idoso, estava há quase trinta dias na UTI da COVID-19 (SarsCoV-2) do hospital em estado gravíssimo, com um alto prognóstico de óbito. A representante da família recebia diariamente a ligação telefônica, na qual era realizada a leitura do boletim médico e $o$ atendimento das demandas psíquicas dos familiares.

Após alguns dias da internação do paciente na UTI, foi revelado, através da assistência psicológica pelo telefone, que os filhos sofriam por não possuírem nenhuma proximidade com a equipe e o hospital. A psicóloga prontamente fez o convite para que eles se reunissem no ambiente hospitalar. Em um ato incomum, os filhos foram recebidos pela coordenadora da psicologia na porta da UTI da COVID-19 (Sars-CoV-2). Nesse momento, o lugar possível mais próximo da presença física do pai. Eles não poderiam adentrar, assim como também não foi possível a saída do médico responsável do setor. Os paramentos médicos e os cuidados com a alta chance de contaminação da UTI da COVID-19 (Sars-CoV-2) não permitiam esse trânsito. Por isso, a psicóloga encarna o possível: faz a leitura diária do boletim médico junto aos filhos e ampara suas demandas psíquicas.

Por que a decisão por essa forma atípica de atendimento psicológico no hospital? Nesse caso, o trabalho da psicologia foi demandado no momento em que o quadro do paciente se agravava. Durante a abordagem, a psicóloga perguntou o que a família compreendia sobre a evolução clínica do paciente. Esses filhos estavam bem conscientes do quadro do pai, mas ainda assim a assistência da psicóloga da instituição hospitalar foi desejado por eles e vivenciado dentro de seus limites reais.

A psicóloga relatou que seu maior objetivo com a intervenção era amparar a família no processo de vivência de um quadro de difícil cura e alta clínica. Uma forma de agir 
preventivamente para humanizar esse momento. Além disso, ela desejava evitar que a única possibilidade de contato com os filhos fosse em uma ocasião derradeira de óbito. Ainda, ela buscava fazer valer a humanização possível diante de uma doença inédita e que evolui cruelmente para algumas pessoas.

No caso acima, dois dias depois da assistência psicológica presencial, o paciente veio à óbito, infelizmente. A pergunta que nos guia: a psicóloga conseguiu alcançar a humanização esperada? Diante dos desfechos ruins, a família costuma agradecer quando se sentiu devidamente amparada. Com essa família, não foi diferente. Houve o encontro no hospital com um dos filhos e o agradecimento veio como índice da assistência psicológica possível. As famílias estão sendo impedidas, em função do alto risco de contágio da COVID-19 (Sars-CoV-2), de acompanhar de perto o processo da doença e do luto. Quais as consequências disso para os sujeitos?

Certamente, algo ainda a ser melhor compreendido. No entanto, pensamos que as consequências psíquicas estão para todos os envolvidos: profissionais de saúde, pacientes e familiares. Uma primeira observação da psicóloga é que as famílias se comportam de forma enfurecida e tendem a culpar o hospital diante do óbito e das limitações do momento, inclusive quanto aos impedimentos atípicos relativos ao velório e ao enterro dos entes queridos. Mais ainda do que nas circunstâncias normais de outros óbitos. Sobre isso, Freud já nos advertia, em seu ensaio Nossa atitude para com a morte (1915/1974a), que o adulto civilizado, que não precise lidar com a morte em caráter profissional, tem dificuldades inatas.

Freud retornou à relação do homem primevo com a morte para tratar da nossa atitude para com a morte. Para ele, havia uma ambivalência do sentimento primitivo frente à morte que ainda está oculta e inconsciente em nós. Um resíduo. Essa contradição faz com que os sujeitos tenham atitudes radicalmente diferentes para com a morte de outras pessoas - de estranhos e de inimigos - e para com sua própria morte. A morte de desconhecidos significa o aniquilamento de alguém pelo qual o sujeito não nutre nenhum afeto ou até odeia. A de si mesmo e a de seus queridos já constitui algo a ser combatido. Ele concluiu que a negação da morte é, portanto, uma atitude convencional e cultural que remonta os primórdios do comportamento humano.

De acordo com ele, o nosso inconsciente aborda a morte quase como o homem primevo. "O que chamamos de nosso 'inconsciente' - as camadas mais profundas de nossas mentes, compostas de impulsos instintuais - desconhece tudo o que é negativo e toda e qualquer negação; nele as contradições coincidem" (Freud, 1915/1974a, p. 335). Por isso, o homem não acredita em sua própria morte e, muitas vezes, age como se fosse um imortal. O homem tende a zombar do perigo numa espécie de reação heroica.

Nesse ensaio, o autor refletia sobre as consequências da morte durante o período da guerra. Para ele, "grande número de mortes simultâneas nos atinge como algo extremamente terrível" (Freud, 1915/1974a, p. 328). Vivenciamos, atualmente, um conflito que não é bélico, mas temos um inimigo invisível e contagioso. De acordo com Freud, momentos como esse alteram o 
tratamento convencional da morte. Grande número de mortes simultâneas nos atinge como algo extremamente terrível. "[A morte] não mais será negada; somos forçados a acreditar nela. As pessoas realmente morrem, e não mais uma a uma, porém muitas, frequentemente dezenas de milhares, num único dia" (Freud, 1915/1974a, p. 329). Esse fato abole o caráter fortuito da morte.

Somado a nossa tendência inconsciente de negar a morte, passamos pelo desconhecimento da doença da COVID-19 (Sars-CoV-2), especialmente no início da pandemia. Atravessamos um processo de desconhecimento considerável da doença e de seus processos, de sua negação e da apropriação do que pode ser feito quanto ao tratamento. No ambiente externo, o uso obrigatório das máscaras por todos, que inicialmente era reservado aos profissionais de saúde e às pessoas infectadas, parece ser um bom índice de como as orientações e os conhecimentos foram evoluindo. No ambiente hospitalar, as máscaras também se multiplicaram e passaram a ser 0 instrumento de proteção de todos.

Uma barreira de proteção usada por muitos, negligenciada por alguns e que espantam outros. Encontramos, na experiência clínica, relatos de pacientes que preferem não sair porque não suportam a visão de muitas pessoas com a máscara. Nesse sentido, relembramos a afirmação freudiana de que "uma vez que quase todos nós ainda pensamos como selvagens acerca [da morte], não é motivo para surpresa o fato de que o primitivo medo da morte é ainda tão intenso dentro de nós e está sempre pronto a vir à superfície por qualquer provocação" (Freud, 1919/1976, p. 302).

Porém, os profissionais da saúde mental estão entre aqueles que não recuam frente o medo da morte. Sabemos que os processos de adoecimento, tratamento, cura ou óbito precisam de suporte psicológico para serem devidamente vivenciados. A grande e inédita questão que a COVID-19 (Sars-CoV-2) traz para o contexto da UTI diz respeito à busca de rituais substitutivos que possam servir de amparo para os familiares dos pacientes infectados. A cada caso, assim como é a clínica psicanalítica, o que é possível? Passaremos a relatar alguns rituais substitutivos que a equipe da UTI da COVID-19 (Sars-CoV-2) da CCMHSP vem empregando, desde o início da pandemia, junto aos familiares de seus pacientes.

Um idoso da UTI foi diagnosticado no boletim médico: medicamento para conforto, em estado terminal. Diante do prognóstico terminal, a psicóloga pediu a presença da família no hospital. Compareceram a filha única e a neta. A filha teve a chance de falar da história de vida do pai: uma elaboração psíquica importante. Ela demandou uma visita de despedida, porém ela apresentava comorbidades significativas diante da COVID-19 (Sars-CoV-2): obesidade, hipertensão e bronquite. A psicóloga conduziu a filha para a conscientização e a própria conclusão da sua impossibilidade de circular em um ambiente de alto risco. A neta teria condições físicas e o desejo de se responsabilizar diante do risco de contaminação.

Nesse atendimento, outras demandas da filha surgiram quanto a falta de humanização diante do recebimento de um "saco preto" e de um caixão lacrado. A ausência de rituais comuns 
de despedida podem tornar o processo de luto ainda mais difícil do que em situações típicas. Por isso, a equipe da psicologia focou em buscar alternativas viáveis e simbólicas que pudessem fomentar a experiência de luto dessa família. Mas o tempo foi cruel e o falecimento do senhor ocorreu antes que a equipe pudesse avaliar a possibilidade da visita de despedida a ser realizada pela neta.

Diante do último suporte psicológico, já no hospital e com o óbito constatado, a pergunta da psicóloga: "eu posso ajudar vocês em mais alguma coisa?". Ao que a filha responde que gostaria da cópia do prontuário do pai: "porque a gente tem que ver...". Ver para crer? Esse foi o arranjo para essa família no dia do óbito. A psicóloga acompanhou o processo de requisição do prontuário e concluiu que essa foi a assistência psicológica possível para o caso.

Porém, para a filha a história não estava concluída. Duas semanas depois, de forma inesperada, ela liga novamente para a psicóloga e retoma a pergunta: "por que eu não pude ver o meu pai na UTI?". Após as explicações sanitárias do fluxo hospitalar frente a COVID-19 (Sars-CoV2), a psicóloga explica ainda que, infelizmente, não houve tempo hábil para a visita de despedida e que ela gostaria de ter atendido ao pedido da neta. E pergunta como está o seu processo de luto. Nesse momento, a filha pôde relatar seu sofrimento e a sua dificuldade em acreditar que o pai faleceu: "é como se ele fosse chegar de uma viagem a qualquer momento". Ela conta que demandou também à funerária ver o pai, mas teve seu pedido negado. Ela se interroga se está assim porque não viu o pai. A pergunta foi sustentada pela psicóloga que a convida para uma outra visita ao hospital para continuar a conversa, caso ela deseje.

Uma outra possibilidade encontrada como substituto ritualístico foi a inserção de fotografias e cartas para serem colocadas nos leitos. Os objetos são plastificados para serem devidamente higienizados e são uma aposta enquanto objetos substitutos às visitas familiares. Para a família, esses objetos funcionam como uma elaboração do processo de adoecimento e tratamento de seu ente querido. Também é um recurso inédito diante de um processo que pode caminhar para o óbito. Em outro caso, a família escreveu uma carta para ser lida pela equipe de enfermagem para o próprio paciente. Entendemos que esses objetos entram em cena como recursos substitutivos às visitas regulares aos pacientes e na vivência de um processo de adoecimento e óbito de um ente querido.

Mais um recurso que foi proposto pela psicóloga intensivista e pela enfermeira da UTI da COVID-19 (Sars-CoV-2) foram as visitas de despedida. Inicialmente, essas visitas não foram viáveis diante do processo de organização dos fluxos hospitalares. Aos poucos, a equipe pôde reavaliar essa posição e concluiu que, se o caso caminhar para o quadro gravíssimo, a família é contatada e é pensado, junto aos seus membros, a forma possível de esvaziar a angústia e viver o processo do adoecimento, do óbito e do luto. A visita de despedida comparece, então, como mais um dos recursos substitutivos mediados pela psicóloga. 
Ressaltamos que cada um desses recursos e possibilidades acontecem numa construção que a psicóloga intensivista faz junto às famílias, no caso a caso. O momento exige urgência, mas a cautela ética da psicanálise é aplicada ainda assim. Na psicanálise, os caminhos subjetivos não devem ser antecipadamente oferecidos. Os recursos existem e a equipe multidisciplinar os construiu dentro das novas possibilidades que a doença permite. Mas eles não são ofertados previamente a todos como mercadorias que podem ser compradas. Há a singularidade das famílias e isso somente uma escuta atenta e um manejo cuidadoso dos casos pode alcançar com precisão. A construção subjetiva diante da doença e da morte no ambiente hospitalar só é possível diante de um profissional atento e qualificado.

A psicóloga apresenta-se para a família: "de que forma eu posso ajudar vocês?". Em um dos casos, a resposta a essa pergunta-convocação foi uma reunião da família para pensar o que eles gostariam de propor. Eles, então, pedem uma visita de despedida, diante do quadro gravíssimo do familiar. Um dos filhos foi o eleito entre eles. De forma paramentada e o mais segura possível, o membro da família foi à UTI para ver o pai à distância. No boletim do dia seguinte, o filho esclarece que foi muito importante para que eles conduzissem a tristeza que estão vivendo. Ele aponta para uma diferença que não sabe nomear entre ter notícias do quadro clínico do pai e de ver o mesmo, ainda que com as limitações. Pensamos que essa importância se deva ao processo natural da vivência do luto para o qual estão se preparando, mediante um prognóstico ruim. A importância parece ser a constatação e o entendimento do quadro terminal. Novamente, ver para crer?

Há casos nos quais o escalonamento para o processo de adoecimento e óbito é ainda mais sutil. Algumas famílias não esboçam o desejo de ver seus familiares. São pessoas que decidem que não querem ver seus parentes nesse estado crítico e em condições de distância limitadas. Ou ainda relatam que "o risco [de contaminação] não vale a pena". Outras têm o desejo, mas não apresentam boas condições de saúde, e portanto, um risco aumentado se houver o contágio. Famílias pequenas podem ter vários membros em situação de alto risco de saúde. Em um desses casos, a demanda da filha foi a seguinte: "qual é a diferença do quadro grave para o gravíssimo?"

A psicóloga entendeu que essa seria uma forma de escalonamento para o momento do óbito. À ela foi oferecida uma conversa com o médico, porém ela justificou que estava em isolamento social e não gostaria de ir ao hospital. A psicóloga, então, propôs munir-se das informações possíveis para que ela entendesse essa diferença. Nesse caso, a família já havia conversado com o médico, mas ainda estava elaborando essa pergunta. Pensamos que a falta de entendimento não era estritamente técnica e sim algo a ser trabalhado subjetivamente. Essa diferença foi trabalhada no momento do boletim com a filha do paciente durante a manhã seguinte. No final da tarde, houve o óbito e a enfermeira da equipe multidisciplinar confirmou que a notícia foi acolhida pela filha de forma serena e consciente. 
Diante de uma outra família na qual os membros não apresentavam condições físicas de fazer a visita de despedida, a psicóloga colheu o seguinte pedido: antecipadamente enviar as roupas que a mãe gostaria de ser enterrada e que ela fosse colocada no "saco preto" com essa vestimenta. Obviamente, o pedido foi acolhido e assim a equipe de enfermagem procedeu, de forma incomum, no momento do óbito. Esse fragmento demonstra que a abertura para os pedidos singulares das famílias deve ser sustentada e pode trazer o amparo no momento da perda.

O trabalho da psicologia aparece em pequenos resultados, como esses que estamos relatando. Mas apostamos que há uma diferença substancial entre receber as informações médicas técnicas de maneira pura e ter suporte psicológico nas angústias e tristezas diante do boletim médico. A única oferta antecipada pela equipe de psicologia do hospital é a de um trabalho subjetivo e orientado para a assistência psicológica das particularidades de cada família.

Notamos que o tipo de vínculo entre os familiares e o paciente é importante para a demanda ou não dos rituais substitutivos e, especialmente, das visitas de despedida. Se os vínculos são mais distantes, normalmente as pessoas optam por não realizarem as visitas. Em casos de vínculos afetivos maiores, ainda que haja o risco de contaminação, a visita é demandada. Somente o envolvimento afetivo pode superar o risco de contaminação e o instinto de autopreservação. Nos demais casos, avaliamos que os rituais substitutivos não são estritamente necessários e desejados.

Em algumas situações, a visita foi demandada, porém não ocorreu por conta da antecipação do próprio óbito. Analisamos que nesses casos, a aceitação da morte do paciente pela família pode ser bastante comprometida. Em um desses momentos, o óbito ocorreu antes do previsto e a irmã da paciente ficou muito abalada e passou a pedir que a sua mãe pudesse ver a filha antes da entrega do corpo para a funerária. Um pedido que no caso do óbito de COVID-19 (Sars-CoV-2) e seus procedimentos sanitários e funerários não pode ser atendido.

A frustração desse caso revela, a nosso ver, a necessidade afetiva dos rituais substitutivos e da visita de despedida diante da impossibilidade do ritual previsto de velar o corpo e amparar os familiares. Todos esses fragmentos das experiências hospitalares durante a epidemia da COVID-19 (Sars-CoV-2) nos fazem refletir se os ritos de despedidas são uma exigência psíquica diante do processo da morte e do luto de um ente querido. A repetição, a cada caso, da demanda de ver os familiares graves nos faz afirmar que sim.

Um fato ocorrido no distrito de Belisário, a 34 quilômetros de Muriaé, nos chamou a atenção. Uma das vítimas da COVID-19 (Sars-CoV-2) foi recepcionada por uma "carreata velório". Nessa adaptação da cerimônia do velório, o padre realizou as exéquias na porta do cemitério (Alves, 2020). A incredulidade diante de uma doença inédita, altamente contagiosa e rapidamente letal para alguns faz com que as pessoas reinventem seus rituais para dar vazão à elaboração psíquica, que quase nunca acompanha a realidade. 
Além da repetição da necessidade dos ritos de despedida, uma outra observação se fez presente no trabalho da psicóloga hospitalar: a transferência. Em psicanálise, "a transferência é impensável, a não ser tomando-se partida do sujeito suposto saber" (Lacan, 1964/1985, p. 239). A psicóloga intensivista passou a ocupar o lugar daquela que pode dizer algo diariamente sobre o familiar. Ela é responsável por escalonar de forma humanizada cada evolução ou involução dos pacientes. Um familiar acompanhado por ela só acreditou quando ouviu dela, de folga no final de semana, que o parente havia falecido. Um funcionário do hospital ligou para o familiar informando o óbito, porém ele entra em contato com a psicóloga dizendo que aguardava "só" uma ligação dela e pedindo que "ela" confirmasse "ou não" o óbito.

O pedido de confirmação do óbito, relatado acima, vem seguido da curiosa fala: "eu fiquei meio com medo de ter a certeza". Sabemos que "a transferência é a atualização da realidade do inconsciente" (Lacan, 1964/1985, p. 139). Suportar o lugar de acolher um familiar que diz que não quer e não pode acreditar na morte, que tem medo, que sente a dor pela perda de seu ente querido é parte da tarefa profissional de humanizar a morte para aquele que inicia seu luto. É receber, a cada ocasião, que o que eu escuto não é o que eu quero escutar. Também que o que eu não vejo, eu não acredito. Ainda, que o que eu olho não é jamais o que eu quero ver.

Em outro dia de trabalho, na porta do hospital, a psicóloga conversa com uma colega e é interpelada por uma senhora: "oi, você se lembra de mim?". Diante da incerteza da psicóloga, a

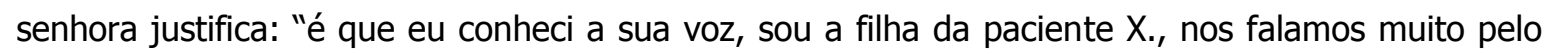
telefone durante a internação dela". Ouvir para crer?

"Numa frase pronunciada, escrita, alguma coisa se estatela. Freud fica siderado por esses fenômenos, e é neles que vai procurar o inconsciente. Ali, alguma outra coisa quer se realizar algo que aparece como intencional, certamente, mas de uma estranha temporalidade" (Lacan, 1964/1985, p. 30). Amparar, através da transferência construída maciçamente em curto período de tempo, os achados do inconsciente é o que orienta o trabalho de psicanálise aplicada da psicóloga intensivista no setor da COVID-19 (Sars-CoV-2).

Freud teve muito a dizer sobre a morte enquanto um fenômeno universal e também como experiência pessoal. Em 1919, ele perdeu subitamente a filha Sophie, de 26 anos, sua "querida Sophie em flor" (Gay, 1989, p. 360), sua "criança radiante", vítima da pneumonia que propagou-se nesse ano e ficou conhecida como gripe espanhola (Jones, 1953/1989, p. 36). "Ela estava grávida de seu terceiro filho. Da mesma forma que um soldado no fronte, Sophie Halberstadt foi uma vítima da guerra, que tornara milhões de pessoas vulneráveis à infecção" (Gay, 1989, p. 360). Sophie deixou dois filhos, um com apenas 1 ano e 1 mês de idade (Jones, 1953/1989, p. 36).

Os biógrafos de Freud relatam que ele nunca superou essa perda familiar. Como era ateísta, procurou o consolo no seu trabalho. Para ele, a vida e o trabalho deveriam continuar enquanto estivermos vivos (Gay, 1923/1989, p. 361). Muitos, inclusive, acreditam que tal encontro com a morte contribuiu para que o sistema psicanalítico freudiano caminhasse para uma ênfase 
sobre a agressão e a morte. "A perda pode reivindicar um papel subsidiário, se não na origem de sua preocupação analítica com a destrutividade, pelo menos na determinação de sua importância" (Gay, 1923/1989, p. 363).

A fragilidade de nossos próprios corpos - além do poder superior da natureza e os relacionamentos sociais - está entre as principais fontes de nossos sofrimentos. Mas para Freud, esse sofrimento deve nos fazer submeter ao inevitável. Isso porque nunca dominaremos completamente a natureza e nosso corpo tem uma estrutura passageira. No entanto, "esse reconhecimento não possui um efeito paralisador. Pelo contrário, aponta a direção para nossa atividade. Se não podemos afastar todo o sofrimento, podemos afastar um pouco dele e mitigar outro tanto: a experiência de muitos milhares de anos nos convenceu disso" (Freud, 1929/1974b, p. 105). Recolhemos essa visão frente a morte em outras palavras que Freud redigiu a Ferenczi, que ficou extremamente preocupado com o impacto da perda de Sophie no espírito do amigo:

Não se preocupe comigo. Sou exatamente o mesmo, com exceção de um pouco mais de cansaço. $\mathrm{O}$ acontecimento fatal, embora penoso, não foi capaz de abalar minha atitude em relação à vida. Durante anos estive preparado para a morte de meus filhos [na batalha]; ocorre então a de minha filha. Como sou profundamente irreligioso, não há ninguém a quem eu possa acusar e sei que não há lugar algum a que se possa endereçar qualquer queixa. 'Des Dienstes ewig gleichgestellte Uhr' [O invariável círculo dos deveres de um soldado] e o 'Daseins süsse Gewohnheit' [Doce hábito da existência] cuidarão de que as coisas continuem como antes. No meu íntimo posso perceber o sentimento de uma profunda ferida narcísica que não será curada. Minha mulher e Annerl estão terrivelmente abaladas, de uma maneira mais humana (Jones, 1953/1989, p. 36-37).

A experiência da psicologia no ambiente hospitalar diante de uma doença inédita e de um momento mundialmente atípico também nos leva a afirmar o desejo pela atividade via aplicação da psicanálise. Confessamos que, ao iniciar esse artigo, sabíamos que tínhamos a psicanálise - e seus fundamentos - como parceira. A psicanálise também é o que orienta o dia a dia da psicóloga diante das urgências subjetivas hospitalares.

No entanto, o inabitual da doença, o desconhecimento de seu tratamento e a falta de perspectiva de sua cura não nos deixava prever aonde chegaríamos. A construção teórica desse artigo acompanhou de perto a prática no hospital e as suas manifestações diárias. Nossa hipótese inicial era vaga. Tínhamos como proposta construir um relato do ofício da psicóloga hospitalar durante a pandemia. Terminamos esse relato com uma hipótese amadurecida derivada de um trabalho sério e responsável junto a familiares que perderam seus entes queridos em função da COVID-19 (Sars-CoV-2). 
Todos os familiares nos confirmaram que os rituais de despedida de um ente querido são uma exigência de nosso psiquismo. No impedimento atípico dos rituais de despedida há que se fazer algo. Alguma resposta diante da falta de sentido que a morte causa. De carreata velório, passando pelas cartas, pelas fotos, pelo último olhar, pela reunião na porta da UTI, pela vestimenta, pela requisição do prontuário ou por simples ligações telefônicas. Nas mais diversas formas, as famílias organizaram-se e a psicóloga intensivista estava ali para encarnar "o invariável círculo dos deveres de um soldado" no seu lugar de amparo e convocação: "de que forma eu posso ajudar vocês?". Afinal, "no doce hábito da existência": "se queres suportar a vida, prepara-te para morte" (Freud, 1915/1974a, p. 339).

\section{Referências Bibliográficas}

Alves, S. (2020, 03 de julho). Artista belisarense é sepultado em meio a muita emoção e protocolos da

saúde. Disponível em: https://www.silvanalves.com.br/portal/2020/07/artista-de-belisario-esepultado-em-meio-a- muita-emocao-e-protocolos-da-saude/.

Freud, S. (1974a). Reflexões para os tempos de guerra e morte. In: Freud [autor]. Obras completas de

S. Freud, v. XIV. Rio de Janeiro: Imago. (Trabalho original publicado em 1915).

Freud, S. (1974b). O mal-estar na civilização. In: Freud [autor]. Obras completas de S. Freud, v. XVII.

Rio de Janeiro: Imago. (Trabalho original publicado em 1929).

Freud, S. (1976). O 'estranho'. In: Freud [autor]. Obras completas de S. Freud, v. XVII. Rio de Janeiro:

Imago. (Trabalho original publicado em 1919).

Gay, P. (1989). Freud: uma vida para nosso tempo. São Paulo: Companhia das Letras, 1989. (Trabalho

original publicado em 1923).

Jones, E. (1989). A vida e a obra de Sigmund Freud. Rio de Janeiro: Imago Editora, v.3, 1989. (Trabalho

original publicado em 1953). 
Lacan, J. (1985). Livro 11: Os quatros conceitos fundamentais da psicanálise. Rio de Janeiro: Jorge Zahar Editora. (Trabalho original publicado em 1964).

Citação/Citation: Bassoli S. Soares, J. \& Matos Rodrigues, P. (nov. 2019 a abr. 2020). A exigência psíquica dos rituais de despedida diante da morte em uma UTI da Covid-19 (Sars-CoV-2). Revista aSEPHallus de Orientação Lacaniana, 15(29), 103-117. Disponível em www.isepol.com/asephallus. Doi: 10.17852/1809-709x.2020v15n29p103-117

Editor do artigo: Tania Coelho dos Santos.

Recebido/Received: 10/03/2019 / 03/10/2019.

Aceito/Accepted: 10/20/2019 / 20/10/2019.

Copyright: @ 2019 Associação Núcleo Sephora de Pesquisa sobre o moderno e o contemporâneo. Este é um artigo de livre acesso, que permite uso irrestrito, distribuição e reprodução em qualquer meio, desde que o autor e a fonte sejam citados/This is an open-access article, which permites unrestricted use, distribution, and reproduction in any medium, provided the author and source are credited. 